\title{
Attractor dynamics in local neuronal networks
}

\author{
Rosa Comas ${ }^{1}$, André Longtin ${ }^{2}$, Jean-Philippe Thivierge ${ }^{1 *}$ \\ From Twenty Second Annual Computational Neuroscience Meeting: CNS*2013 \\ Paris, France. 13-18 July 2013
}

A hallmark feature of cortical networks is the presence of synaptic motifs, defined as ensembles of neurons whose synaptic pattern follows a particular configuration [1]. Simulated networks of neurons whose excitatory synapses follow a three-node "relay" motif (Figure 1A)the most frequent motif in primate visual cortex- exhibit synchronization with zero time lag [2], a form of activity reported in a spectrum of experiments [3]. Here, using simulations of leaky integrate-and-fire networks (LIF) as well as mean-field stability analyses, we show that this relay motif promotes the emergence of a limit cycle whose period is determined by intrinsic properties of the model (Figure 1B). While cortical recordings show evidence of limit-cycle oscillations [4], this behavior is typically transient in non-pathological states. The question thus arises, of how to generate transient yet precise synchronization under different forms of motif connectivity. To address this question, we introduce a mechanism of selective gain inhibition by which cortical circuits may disengage from a strict limit cycle behavior. This mechanism works by tuning the gain inhibition [5] of a selective population of neurons in the model. In a first

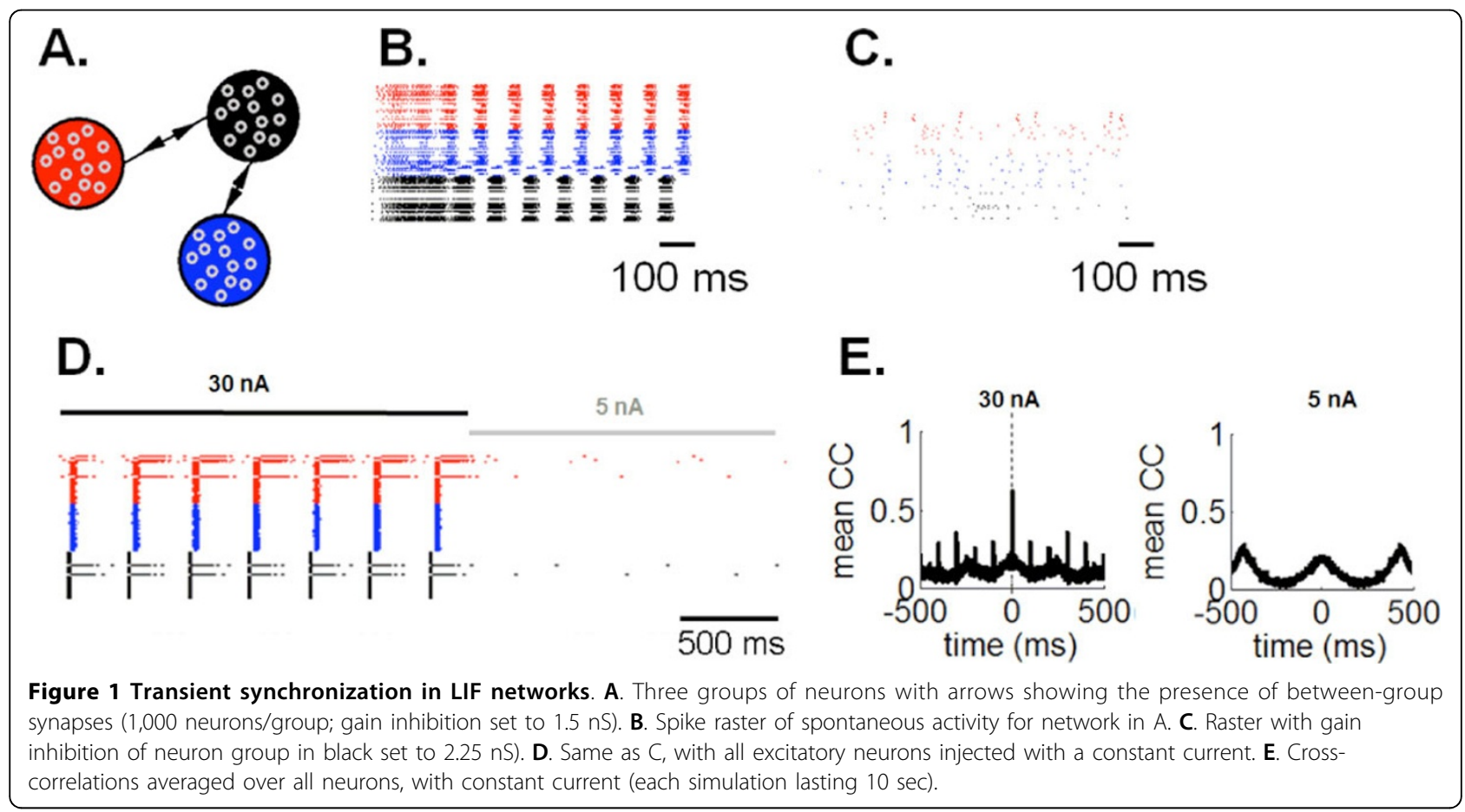

\footnotetext{
* Correspondence: jthivier@uottawa.ca

'School of Psychology, University of Ottawa, Ottawa, Ontario K1N 6N5,

Canada

Full list of author information is available at the end of the article
}

C Biomed Central

ㄷ 2013 Comas et al; licensee BioMed Central Ltd. This is an Open Access article distributed under the terms of the Creative Commons Attribution License (http://creativecommons.org/licenses/by/2.0), which permits unrestricted use, distribution, and reproduction in any medium, provided the original work is properly cited. 
series of simulations, we show that applying selective gain inhibition to one population of a network (Figure 1A, shown in black) disengages the network from a limit cycle behaviour (Figure 1C). Next, we examine the effect of selective gain inhibition on a network's response to an incoming stimulus and show that transient synchronization arises in response to a time-delimited input current (Figure 1D). Selective gain inhibition enables stimulusinduced synchronization under strong stimulation and suppresses zero-lag synchrony under weak stimulation (Figure 1E). Transient synchronization would not be possible without selective gain inhibition, given that a network configured with a "relay" motif follows a limit cycle attractor (Figure 1B). We conclude that a "relay' motif of connectivity imposes strict constraints on the types of dynamics produced by a network under both spontaneous and evoked states. Going further, results of simulations suggest that a mechanism of selective gain inhibition breaks the rigid constraints imposed by synaptic connectivity, providing flexible and transient responses to incoming stimuli.

\section{Acknowledgements}

This work was supported by a grant from the NAKFI Keck Future Initiatives to J.P.T. as well as start-up funds to J.P.T. from the University of Ottawa. Authors are thankful to Eric Shea-Brown for useful discussions.

\section{Author details}

'School of Psychology, University of Ottawa, Ottawa, Ontario K1N 6N5, Canada. ${ }^{2}$ Department of Physics, University of Ottawa, Ottawa, Ontario K1N $6 \mathrm{~N} 5$, Canada.

Published: 8 July 2013

\section{References}

1. Song S, Sjostrom PJ, Reigl M, Nelson S, Chklovskii DB: Highly nonrandom features of synaptic connectivity in local cortical circuits. PLOS Biol 2005, 3(3):e68.

2. Vicente R, Gollo LL, Mirasso CR, Fischer I, Pipa G: Dynamical relaying can yield zero time lag neuronal synchrony despite long conduction delays. Proc Natl Acad Sci USA 2008, 105(44):17157-17162.

3. Benda J, Longtin A, Maler L: A synchronization-desynchronization code for natural communication signals. Neuron 2006, 52(2):347-358.

4. Rodriguez E, George N, Lachaux JP, Martinerie J, Renault B, Varela FJ: Perception's shadow: long-distance synchronization of human brain activity. Nature 1999, 397(6718):430-433.

5. Vogels TP, Abbott LF: Gating multiple signals through detailed balance of excitation and inhibition in spiking networks. Nat Neurosci 2009, 12(4):483-491.

doi:10.1186/1471-2202-14-S1-P386

Cite this article as: Comas et al:: Attractor dynamics in local neuronal networks. BMC Neuroscience 2013 14(Suppl 1):P386.

\section{Submit your next manuscript to BioMed Central and take full advantage of:}

- Convenient online submission

- Thorough peer review

- No space constraints or color figure charges

- Immediate publication on acceptance

- Inclusion in PubMed, CAS, Scopus and Google Scholar

- Research which is freely available for redistribution

Submit your manuscript at www.biomedcentral.com/submit
C Biomed Central 